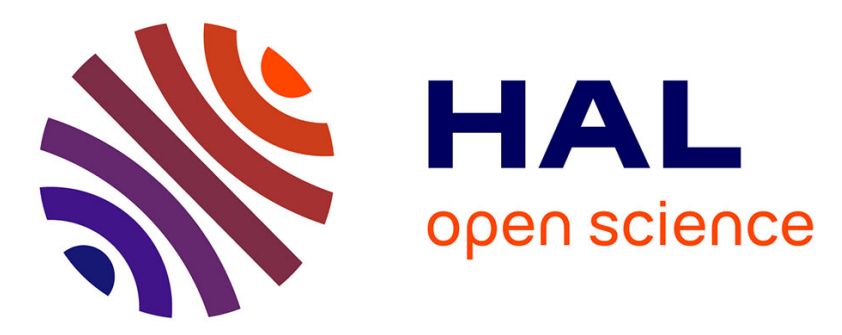

\title{
Exploratory study of the three-dimensional morphological variation of the jaw associated to teeth loss
}

Sonia Guevara Perez, Michel Behr, Lionel Thollon

\section{- To cite this version:}

Sonia Guevara Perez, Michel Behr, Lionel Thollon. Exploratory study of the three-dimensional morphological variation of the jaw associated to teeth loss. Journal of Stomatology, Oral and Maxillofacial Surgery, 2019, 120 (6), pp523-528. hal-02562623

\section{HAL Id: hal-02562623 \\ https://hal-amu.archives-ouvertes.fr/hal-02562623}

Submitted on 5 Jul 2021

HAL is a multi-disciplinary open access archive for the deposit and dissemination of scientific research documents, whether they are published or not. The documents may come from teaching and research institutions in France or abroad, or from public or private research centers.
L'archive ouverte pluridisciplinaire HAL, est destinée au dépôt et à la diffusion de documents scientifiques de niveau recherche, publiés ou non, émanant des établissements d'enseignement et de recherche français ou étrangers, des laboratoires publics ou privés. 


\section{Exploratory study of the three-dimensional morphological variation of the jaw associated to teeth loss.}

Sonia V. Guevara Perez ${ }^{\mathrm{a}, \mathrm{b}}$, Michel Behr ${ }^{\mathrm{b}}$, Lionel Thollon ${ }^{\mathrm{b}}$

a Universidad Nacional de Colombia. Department of Oral Health. 11001 BogotaColombia

b IFSTTAR-Laboratory of Applied Biomechanics UMR T24, Aix-Marseille Université, 13916 Marseille, France.

\section{e-mail adresess:}

Sonia V. Guevara Perez: svguevarap@unal.edu.co; sonia.guevara-perez@ifsttar.fr

Lionel Thollon: lionel.thollon@ifsttar.fr

Michel Behr: michel.behr@ifsttar.fr

\section{CORRESPONDING AUTHOR:}

S. V. Guevara Pérez

Aix-Marseille Université, IFSTTAR, LBA UMR T24, F-13016, Marseille

Bd. P. Dramard, Faculty of Medicine, North Sector

13916 Marseille Cedex 20. Tél : +33 (0)4 91658000 Fax : +33 (0)4 91658019

FRANCE

Email : svguevarap@unal.edu.co;sonia.guevara-perez@ifsttar.fr

Funding: This research was partially funded by a mobility grants program (ColfuturoASCUN-Embassy of France-Colombia) 


\title{
Exploratory study of the three-dimensional morphological variation of the jaw associated to teeth loss.
}

\begin{abstract}
Purpose: The aim of this study is to evaluate the morphological variability in mandibles with different types of edentulism, comparing the use of traditional morphometrics and tridimensional geometric morphometrics.

Methods: Traditional morphometrics and geometric morphometrics (GM) exploratory analysis, by principal components (PCs) and PC scores, were performed on a sample of 24 cadaveric hemi mandibles. A digital reconstruction of 3D surfaces of each specimen was obtained by CT scans segmentation. The mandibles were divided in three groups: full dentition (G1), partial edentition (G2) and total edentition (G3). The results of the two methods were compared in relation to the morphological variability determined with each method.
\end{abstract}

Results: Both methods were consistent in terms of morphological variability between the defined groups. The main shape variations observed were a decrease in mandibular body height, a widening of the cross sectional morphology on the symphysis, a shorten-narrowed Ramus and a deeper sigmoid notch, in the partially or totally edentition groups, compared to the full dentition group.

Discussion: The general patterns of morphological variations associated with edentulism that have been reported in literature could be visualized with GM method, which had not been previously used for this purpose. The GM methods could offer a more detailed definition of shape variations, which is critical in a clinical context. Moreover, GM allowed defining configurations of mean morphologies and an image library with different types of morphological variations.

KEYWORDS: Morphometrics geometrics; mandible; tooth loss; image processing 


\section{INTRODUCTION}

Many factors have been related to morphologic variability of human mandible, as age, gender, genetic and functional factors. [1-6] Mandibular bone experience morphological changes through postnatal growth, due to a process that involves a selective resorption and deposition of bone, to bring about the required three-dimensional growth changes.[7] The development of the mandible is influenced by dental eruption, skull development and masticatory forces. [8, 9] In the adult age, the presence or absence of teeth is the main factor determining their morphology. [10-12] Some recent studies have also stated that the dental condition plays a more important role in the mandibular morphological changes than age or gender.[12-14]

Many local and systemic factors have been proposed to influence post-extraction resorption in the mandible. These local factors can be functional, such as the presence or absence of prostheses and associated components, the absence of mechanical stress and muscular strength. They can be anatomical, such as facial shape, mandibular morphology, bone quality, muscle attachments. Finally, these local factors can also be inflammatory, such as periodontal disease, pre-existing infections, and local inflammatory mediators. Mainly associated systemic factors are age and gender, bone quality, levels of hormone regulators of bone metabolism and calcium level.[10]

The remodeling process that occurs with tooth loss was studied previously, through the observation of the distribution and patterns of resorptive and repository fields in mandibles at different stages of edentition.[11] More recently, expected patterns for modifications in the alveolar shape after tooth loss were proposed.[15] The process of atrophy of alveolus is cumulative and irreversible, and depends on numerous factors; generating an inter-individual variation in post-extraction remodeling.[10, 16]

Numerous studies have evaluated the mandibular morphological changes associated with edentition by traditional morphometrics (linear and angle measurements). [11, 12, $14,16-19]$ In recent years the generalized use of 3D medical images is offering new possibilities in using advanced 3D morphometric tools.[20]

Geometric morphometrics (GM) is a multivariate approach that studies morphological variation in terms of the relative location of anatomical landmarks in the Euclidean space. The most used method in GM is the Procrustes superimposition analysis [20, $21]$, that consists in locating different landmarks coordinates in the same reference system by three geometrical transformations: translation, scaling and rotation. When non-shape variation is eliminated, the variables become shape variables and may be used to compare samples statistically. This method allows exploring shape variations 
of an anatomic structure, independently of size variations; and the variation can be visualized in their anatomical context, providing a wide range of applications in the fields of biology, genetics, phylogeny and anthropology. [22, 23]

In this context, the aim of this study was to evaluate the morphological variability in mandibles with diverse types of edentulism, comparing the use of traditional morphometrics and tridimensional geometric morphometrics (GM).

\section{MATERIALS AND METHODS}

A sample of 24 human hemi mandibles dissected from 12 cadavers ( 8 males, 4 females) with average age $74 \pm 8$ from the Thanatopraxy Department of the Faculty of Medicine of Aix-Marseille University, were selected for the study. The protocol satisfies the ethical standards of the University. Inclusion criteria were as follows: adults over 50 , at different stages of edentition, no visible bone pathology or bone trauma, and no dental implants. Both hemi mandibles of each specimen was measured, but for GM analysis, each side was defined as a classifier for each specimen and not as independent variable, in agreement with previous recommendations.[24] The specimens were then classified in three groups: G1 (full dentition) (N=8), G2 (partial edentition)( $\mathrm{N}=6)$, $\mathrm{G} 3$ (total edentition) $(\mathrm{N}=10)$. A CT Scan was performed on each specimen using a SIEMENS Somatom Sensation Cardiac 64® scan (SIEMENS Munich, Germany) (RAI orientation, data collection diameter $500 \mathrm{~mm}$, reconstruction diameter 132mm, 512x512x455 pixels, slice thickness 0.6mm, KVP 120, 304mA, 1000 msec). To obtain 3D digital models, the DICOM files were segmented with MIMICS (Materialise, Leuven, Belgium). The segmentation process consisted in isolating a target tissue or region based on its cortical and trabecular bone density thresholds. A 3D surface reconstruction was then calculated based on the series of bi-dimensional masks, with a quality configuration of a smoothing factor set to 0,5 and interpolation set to "by contour". For toothed mandibles, teeth were eliminated from the reconstruction process by editing the bi dimensional mask with a Boolean subtraction of the tooth crown tissues. The 3D surface mesh obtained for each specimen was recorded in .stl format. All mandibles were oriented with their geometric center as the origin 0 in the three axes $\mathrm{X}, \mathrm{Y}$ and $\mathrm{Z}$; positioned in a left hemi mandible view and transformed into polygon file format (.ply) with 3D editor (Microsoft Corp. Washington, UE).

\subsection{Morphometric analysis}

For traditional morphometrics, eleven distances and angular measures have been taken, on the mandibles, six of which were bilateral. The measurement protocol is 
illustrated in Fig.1a. The software PAST [25] was used for summary statistics and Principal component analysis (PCA) of the samples.

For GM, 3D coordinates data was collected for 18 landmarks that are illustrated in Fig.1b, using Landmark Editor software V 3.0. [26] The landmarks were selected to best cover the overall shape of the mandibular body and ramus. However after the measurement errors, only 13 landmarks were kept for the subsequent analysis (Fig.1b). The same evaluator measured all hemi-mandibles twice, at two different moments.

A significant amount of variation among replicas could be attributed to repetitions, if the mean square for the error repetition value was found $10 \%$ higher than the mean square for the "individual" term. [27] To estimate the measurement error of each landmark and the linear and angle measurement, the software PAST [25] and the raw coordinates of the repetitions were used to evaluate the absolute mean error and to compute the intraclass correlation coefficient (ICC) for each.

\subsection{Geometric morphometrics analysis}

The GM analysis was performed with open source software Morpho J V 1.06. [28] Landmarks coordinates were superimposed using the Generalized Procrustes Analysis (GPA) method and projected to the shape tangent space. This method is based on superimposing landmark configurations using least-square estimates for rotation and translation parameters with configurations scaled in a common unit size (centroid size). The process is iterated to compute the general mean shape and the mean shape for each group, $[22,23]$ so size and shape can be analyzed separately. Kruskal-Wallis test was used on centroid size data to test for significant size differences among groups. [25] The fitted coordinates after GPA were analyzed by a principal component analysis (PCA) of Procrustes ANOVA, using side as a classifier for effect in the analysis. In this way only the symmetric component for computing Procrustes and covariance component due to Individuals was shown. The PCA would explain progressively smaller amounts of the total morphologic variance. Visualization of shape variation of the total data set and mean morphology of each group were performed by warping a 3D surface model of mandible using the landmark Editor software [26, 29] and the distance between average morphologies was computed using the mesh distance tool in Meshlab software. The detailed methods of geometric morphometry used are shown in a previous publication. [30] 


\section{RESULTS}

Repeatability error by Procrustes ANOVA was found lower than $1 \%(p<0,0001)$. The landmarks Rpost, AntGo, RetMollnt, Rant and CoSup (see Fig.1b) were excluded because of an ICC lower than 0.85 and/or a mean difference between repetitions superior to $1 \mathrm{~mm}$, in at least one axis. All other landmarks and linear measurements gave an ICC over 0.9 and mean differences under $0.9 \mathrm{~mm}$. The Kruskal-Wallis test for equal medians on the Centroid size data did not reveal a significant difference between the three groups $(p=0.76)$.

The main morphological variations observed by means of traditional morphometry are summarized in Table 1, with the averages of each variable compared for each group.

Fig. 2 shows the bar graphic for means of length and angle measurements for the three groups. The main shape variations in G2 and G3 compared with G1 were: decrease in the height of the mandibular mid body by $24 \%$ in G2 and $41 \%$ in G3, decrease of symphysis height by $16 \%$ in G2 and $37 \%$ in G3, decrease in posterior mandibular height by $30 \%$ and a deeper sigmoid notch in both groups, a widening $(7,7 \%)$ of the cross sectional morphology on the symphysis in G3. The ten first PCs eigenvalues of the fitted coordinates after PCA of Procrustes ANOVA (GM) and PCA for linear and angular measures (Traditional morphometrics) are shown in Table 2.

The results of variability between groups by GM are given by the first three PCs that provide a good approximation of the total variation (72,5\%). For Traditional morphometrics, the first three PCs explain $88.9 \%$ of the variation. The plots of PC scores and wire frames of the three first PCs are shown in Fig.3a, and Fig.3b with the 3D shape changes associated to each PC axis for GM analysis. PC1 accounts for $46.98 \%$ of the shape variation, and mainly stands for the change in the mandibular body height on the anterior and posterior regions, the cross-section morphology of the symphysis and the vertical projection of the coronoid process (Fig.3a). The landmarks with the higher coefficients for PC1 were in this order: 5,8,6 and 11. The plots show that PC1 well discriminates the three groups, with G3 placed in the negative area, G1 in the positive area, and G2 in between. PC2 reveals changes in the mental protrusion, ramus morphology, sigmoid notch length and gonial angle (Fig.3a). The landmarks with greatest coefficients for PC2 were 9, 10 and 8. The plots show $\mathrm{G} 1$ in a rather negative area, G3 in the positive area while G2 remains close to the mean. PC3 shows variations in the ramus width, sigmoid notch length and gonial angle (Fig.3a). The landmarks with greater coefficient for PC3 were 12,2 and 5. 
The 3D configuration of each group obtained by morphing a surface mean model are shown in Fig. 4a and the superimposition of the meshes between G1 and G3 are shown in Fig. 4b.

\section{DISCUSSION}

In this study, the edentulism state was found to be associated with 3D morphologic variations identified in the mandibular bone. Given the regular use of 3D visualization tools in clinicians offices nowadays, but the underutilization of the information that could be extracted, GM could offer a more detailed and adapted tool to the clinicians in the context of their practice for representing and visualizing the shape variations of the mandibular bone.

The variations in edentulous mandibular morphology have been evaluated previously mostly with the use of panoramic or lateral radiographs [16-18] and by direct measurements in dry skulls [12-15], limiting the variables to distances projected in 2D. More recently [31], the use of images of dental CT has allowed the evaluation by means of 3D measurements of mandibular morphology in different types of edentulism; finding a different pattern of changes in height and width with a sequential loss of height at the alveolar level, with a relatively stable width in the posterior mandibular areas, which agrees with the results found in the present study.

The main variations observed both with traditional morphometrics and with GM were localized in the body height, with a higher corpus in the dentate group (G1) and a sequential loss of alveolar bone in the group with partial edentition (G2) and total edentition (G3). The mesh difference between G1-G3 reveals a significant difference among average configurations, mainly in the mandibular body height, with a narrower but higher ramus and a deeper sigmoid notch, and a wider symphysis in G3. Between G1-G2, the differences in the body height are more significant in the posterior than anterior regions, with a more acute gonial angle in $\mathrm{G} 1$. There is also a narrower ramus in G2, a higher position of the coronoid process and a deeper sigmoid notch in G3. Between G2-G3, the vertical differences are more significant in the anterior region, and there is a difference in the gonial angle, with a more acute angle in G3. No clear differences are observed in the ramus. The results observed numerically by traditional morphometrics were found in good agreement with results observed visually by GM. In both cases, morphologic variation was expected as previously reported [11, 15, 16 , 31 ], usually explained as a result of an alveolar involution in the inferior and posterior directions, where the alveolar process is gradually reduced to a residual ridge. 
The cross-sectional morphology of the symphysis revealed a difference between groups, with not only a decrease in height but also a widening in the groups with partial or total edentulism. In agreement with these observations are the depository fields, on the buccal and lingual sides of the mandibular basal body, with an increase of the corpus breadth observed by Enlow [11]. However, Cawood and Howell [15] reported that the shape of the basilar process of the mandible remains relatively stable despite significant changes in the alveolar process in both the vertical and horizontal axes. The first two PCs not only indicate the vertical changes in the mandibular morphology associated to edentulousness, but also the alterations on the mental protrusion, ramus and sigmoid notch morphology. The changes in the mental protuberance that have been described previously as a depository remodeling field [11] were also observed here in the chin region.

Additionally, the GM analysis revealed a higher location of the coronoid process, with a deeper sigmoid notch, in contrast with what has been reported previously [14] where no differences between mandibular notches were found.

Changes relative to a forward rotation and downward angulation of the mandibular corpus associated with edentulism $[14,17]$ were observed on the PC3; nevertheless, only the partial edentition group displayed a wider gonial angle than the total or nonedentulous groups. In the present study the opening of the gonial angle described in previous works was not clearly observed, the cause of which possibly being that the point of reference used here was the lateral condyle and not the posterior condyle, perhaps disguising subtle changes at the neck or condylar head that influence the gonial angle.

Recently Sella-Tunis et al.[6] reported a strong correlation of muscle size and mandibular shape in young adult individuals, which was not evidenced by traditional morphometry.

As anticipated, the edentition was found to affect in a predictable way the mandibular morphology. The main shape variations observed by the two methods were a decrease of mandibular body height, a widening in the cross sectional morphology on the symphysis, a shorten-narrowed Ramus and a deeper sigmoid notch, in the partial or total edentition groups, compared to the full dentition group. In this study, the small number of samples made it difficult to statistically record significant results and to correlate the results to other variables such as gender or function. Nevertheless, in an exploratory approach, the general patterns of morphological variations associated with edentition which have been reported in literature could be measured by traditional 
morphometrics and visualized with 3D GM. This methodology should provide a more accurate and detailed definition of shape variations, which is critical in a clinical context. It is also necessary to increase the number of samples to improve statistical power.

Ethical approval: All procedures performed in studies involving human cadavers were in accordance with the ethical standards of the institutional research committee and with the 1964 Helsinki declaration and its later amendments or comparable ethical standards.

Informed consent: This article does not contain patient data.

Declarations of interest: none.

\section{ACKNOWLEDGMENTS}

Authors would like to acknowledge the contribution of Dr. Kathia Chaumoître (Radiology Service-Hospital Nord-Marseille) for her collaboration.

\section{REFERENCES}

[1] Morant GM, Adyanthaya NK. A BIOMETRIC STUDY OF THE HUMAN MANDIBLE. Biometrika. 1936;28(1-2):84-122.

[2] Humphrey LT, Dean MC, Stringer CB. Morphological variation in great ape and modern human mandibles. J Anat. 1999;195 ( Pt 4):491-513. PubMed PMID: 10634689; PubMed Central PMCID: PMCPMC1468021.

[3] Nicholson E, Harvati K. Quantitative analysis of human mandibular shape using threedimensional geometric morphometrics. Am J Phys Anthropol. 2006;131(3):368-83. doi: 10.1002/ajpa.20425. PubMed PMID: 16617436.

[4] Puisoru M, Forna N, Fatu AM, Fatu R, Fatu C. Analysis of mandibular variability in humans of different geographic areas. Annals of Anatomy-Anatomischer Anzeiger. 2006;188(6):547-54. doi: 10.1016/j.aanat.2006.05.015. PubMed PMID: WOS:000242378700010.

[5] Swasty D, Lee J, Huang JC, Maki K, Gansky SA, Hatcher D, et al. Cross-sectional human mandibular morphology as assessed in vivo by cone-beam computed tomography in patients with different vertical facial dimensions. American Journal of Orthodontics and Dentofacial 
Orthopedics. 2011;139(4, Supplement):e377-e89. doi:

http://dx.doi.org/10.1016/j.ajodo.2009.10.039.

[6] Sella-Tunis T, Pokhojaev A, Sarig R, O'Higgins P, May H. Human mandibular shape is associated with masticatory muscle force. Sci Rep. 2018;8(1):6042. Epub 2018/04/16. doi: 10.1038/s41598-018-24293-3. PubMed PMID: 29662127; PubMed Central PMCID: PMCPMC5902585.

[7] Enlow DH. A morphogenetic analysis of facial growth. Am J Orthod. 1966;52(4):283-99. PubMed PMID: 5217789.

[8] Coquerelle M, Bookstein FL, Braga J, Halazonetis DJ, Weber GW, Mitteroecker P. Sexual dimorphism of the human mandible and its association with dental development. Am J Phys Anthropol. 2011;145(2):192-202. Epub 2011/03/01. doi: 10.1002/ajpa.21485. PubMed PMID: 21365613.

[9] Franklin D, Cardini A, O'Higgins P, Oxnard CE, Dadour I. Mandibular morphology as an indicator of human subadult age: geometric morphometric approaches. Forensic Sci Med Pathol. 2008;4(2):91-9. doi: 10.1007/s12024-007-9015-7. PubMed PMID: 19291478.

[10] Kingsmill VJ. Post-extraction remodeling of the adult mandible. Critical Reviews in Oral Biology \& Medicine. 1999;10(3):384-404. PubMed PMID: WOS:000085741400009. [11] Enlow DH, Bianco HJ, Eklund S. REMODELING OF EDENTULOUS MANDIBLE. Journal of Prosthetic Dentistry. 1976;36(6):685-93. doi: 10.1016/0022-3913(76)90035-4. PubMed PMID: WOS:A1976CN33300012.

[12] Chrcanovic BR, Abreu MH, Custódio AL. Morphological variation in dentate and edentulous human mandibles. Surg Radiol Anat. 2011;33(3):203-13. Epub 2010/09/29. doi: 10.1007/s00276-010-0731-4. PubMed PMID: 20878404.

[13] Ozturk CN, Ozturk C, Bozkurt M, Uygur HS, Papay FA, Zins JE. Dentition, bone loss, and the aging of the mandible. Aesthet Surg J. 2013;33(7):967-74. Epub 2013/09/10. doi: 10.1177/1090820X13503473. PubMed PMID: 24023258.

[14] Hutchinson EF, Farella M, Kramer B. Importance of teeth in maintaining the morphology of the adult mandible in humans. Eur J Oral Sci. 2015;123(5):341-9. Epub 2015/08/19. doi: 10.1111/eos.12203. PubMed PMID: 26287722.

[15] Cawood JI, Howell RA. A classification of the edentulous jaws. International Journal of Oral and Maxillofacial Surgery. 1988;17(4):232-6. doi: http://dx.doi.org/10.1016/S09015027(88)80047-X.

[16] Mercier P, Lafontant R. Residual alveolar ridge atrophy: classification and influence of facial morphology. J Prosthet Dent. 1979;41(1):90-100. PubMed PMID: 281529. 
[17] Huumonen S, Sipila K, Haikola B, Tapio M, Soderholm AL, Remes-Lyly T, et al. Influence of edentulousness on gonial angle, ramus and condylar height. Journal of Oral Rehabilitation. 2010;37(1):34-8. doi: 10.1111/j.1365-2842.2009.02022.x. PubMed PMID: WOS:000272581700006.

[18] Uma M, Shetty R, Shenoy KK. Cephalometric: evaluation of influence of edentulousness on mandibular morphology: a comparative study. J Indian Prosthodont Soc. 2013;13(3):269-73. doi: 10.1007/s13191-012-0213-y. PubMed PMID: 24431746; PubMed Central PMCID: PMCPMC3732722.

[19] Okşayan R, Asarkaya B, Palta N, Şimşek I, Sökücü O, İşman E. Effects of edentulism on mandibular morphology: evaluation of panoramic radiographs. ScientificWorldJournal. 2014;2014:254932. doi: 10.1155/2014/254932. PubMed PMID: 25202718; PubMed Central PMCID: PMCPMC4151542.

[20] Mantini S, Ripani M. Modern morphometry: new perspectives in physical anthropology. $\mathrm{N}$ Biotechnol. 2009;25(5):325-30. Epub 2009/04/05. doi: 10.1016/j.nbt.2009.03.009. PubMed PMID: 19491048.

[21] Toro Ibacache MV, Manriquez Soto G, Suazo Galdames I. Morfometría Geométrica y el Estudio de las Formas Biológicas: De la Morfología Descriptiva a la Morfología Cuantitativa. International Journal of Morphology. 2010;28:977-90.

[22] Adams DC, Rohlf FJ, Slice DE. Geometric morphometrics: Ten years of progress following the 'revolution'. Italian Journal of Zoology. 2004;71(1):5-16. doi: $10.1080 / 11250000409356545$.

[23] Klingenberg CP. Visualizations in geometric morphometrics: how to read and how to make graphs showing shape changes. Italian Journal of Mammalogy. 2013;24(1):15-24. Epub 201303-05. doi: 10.4404/hystrix-24.1-7691.

[24] Klingenberg CP, Barluenga $M$, Meyer $A$. Shape analysis of symmetric structures: quantifying variation among individuals and asymmetry. Evolution. 2002;56(10):1909-20. PubMed PMID: 12449478.

[25] Hammer $\varnothing$, Harper DAT, Ryan PD. PAST: Paleontological statistics software package for education and data analysis. Palaeontologia Electronica. 2001;4(1):9.

[26] Wiley DF, N. Amenta, D. A. Alcantara, D. Ghosh, Y. J. Kil, E., Delson WH-S, F. J. Rohlf, K. St. John, and B. Hamann, editors. Evolutionary Morphing. Proceedings of IEEE Visualization 2005 VIS '05; 2005; Minneapolis.

[27] Fruciano C. Measurement error in geometric morphometrics. Dev Genes Evol. 2016;226(3):139-58. Epub 2016/04/01. doi: 10.1007/s00427-016-0537-4. PubMed PMID: 27038025. 
[28] Klingenberg CP. MorphoJ: an integrated software package for geometric morphometrics. Mol Ecol Resour. 2011;11(2):353-7. Epub 2010/10/05. doi: 10.1111/j.1755-0998.2010.02924.x. PubMed PMID: 21429143.

[29] Drake AG, Klingenberg CP. Large-scale diversification of skull shape in domestic dogs: disparity and modularity. Am Nat. 2010;175(3):289-301. doi: 10.1086/650372. PubMed PMID: 20095825.

[30] Guevara Perez SV, de la Rosa Castolo G, Thollon L, Behr M. A 3D characterization method of geometric variation in edentulous mandibles. Morphologie. 2018 Dec;102(339):255-262. doi: 10.1016/j.morpho.2018.08.001. PubMed PMID:30197034.

[31] Sbordone C, Toti P, Brevi B, Martuscelli R, Sbordone L, Di Spirito F. Computed tomography-aided descriptive analysis of maxillary and mandibular atrophies. J Stomatol Oral Maxillofac Surg. 2018 Dec. In press. https://doi.org/10.1016/j.jormas.2018.12.006. 


\section{TABLES}

Table 1. Mean data of measures variables for each group: G1 full dentition mandibles. G2 partial edentition and G3 total edentition. Distances are shown in $\mathrm{mm}$ and angle in grades. The landmarks definition are shown in Fig.1. The relative variations are showing in percentage of the G1 measure.

\begin{tabular}{|c|c|c|c|c|}
\hline & G1 & G2 & G3 & Morphologic variation \\
\hline $\begin{array}{l}\text { Symphysis High } \\
\text { (Sy-InfDe distance) }\end{array}$ & 32.27 & $\begin{array}{c}27.09 \\
(-16.05 \%)\end{array}$ & $\begin{array}{c}20.18 \\
(-37.46 \%)\end{array}$ & $\begin{array}{c}\text { Decrease in symphysis } \\
\text { high }\end{array}$ \\
\hline $\begin{array}{l}\text { Body height at mental hole } \\
\text { (Sup M-InfM distance) }\end{array}$ & 29.51 & $\begin{array}{c}22.40 \\
(-24.09 \%)\end{array}$ & $\begin{array}{c}17.24 \\
(-41.57 \%)\end{array}$ & $\begin{array}{l}\text { Decrease in mid corpus } \\
\text { high }\end{array}$ \\
\hline $\begin{array}{l}\text { Body height at retro-molar level } \\
\text { (RetMolExt-AntGo distance) }\end{array}$ & 26. 14 & $\begin{array}{c}18.11 \\
(-30.71 \%)\end{array}$ & $\begin{array}{c}18.12 \\
(-30.68 \%)\end{array}$ & $\begin{array}{l}\text { Decrease in posterior } \\
\text { corpus high }\end{array}$ \\
\hline $\begin{array}{l}\text { Symphysis width } \\
\text { (Me-MeSp distance) }\end{array}$ & 16.45 & $\begin{array}{c}15.49 \\
(-5.8 \%)\end{array}$ & $\begin{array}{c}17.72 \\
(+7.72 \%)\end{array}$ & $\begin{array}{c}\text { Wider symphysis in totally } \\
\text { edentulous }\end{array}$ \\
\hline $\begin{array}{l}\text { Ramus width } \\
\text { (Rant-Rpost distance) }\end{array}$ & 33.77 & $\begin{array}{c}26.01 \\
(-22.97 \%)\end{array}$ & $\begin{array}{c}30.01 \\
(-11.13 \%)\end{array}$ & $\begin{array}{l}\text { Narrow ramus in partially } \\
\text { and totally edentulous }\end{array}$ \\
\hline Gonial angle $\left(^{\circ}\right)$ & 118.48 & $\begin{array}{c}124.60 \\
(+5.16 \%)\end{array}$ & $\begin{array}{c}117.69 \\
(-0.66 \%)\end{array}$ & Wider angle for G2 \\
\hline $\begin{array}{l}\text { Mandibular body length } \\
\text { (Me-Go distance) }\end{array}$ & 88.46 & $\begin{array}{c}78.60 \\
(-11.14 \%)\end{array}$ & $\begin{array}{c}83.64 \\
-5.44 \%)\end{array}$ & Shorter corpus \\
\hline $\begin{array}{l}\text { Total mandibular length } \\
\text { (Me-Colsup distance) }\end{array}$ & 128.04 & $\begin{array}{l}119.20 \\
(-6.90 \%)\end{array}$ & $\begin{array}{c}120.94 \\
(-5.54 \%)\end{array}$ & $\begin{array}{l}\text { Decrease in mandibular } \\
\text { length }\end{array}$ \\
\hline
\end{tabular}


Table 2. Principal Components (PCs) eigenvalues for the ten first PCs of Procrustes ANOVA for individuals compared with PCA for traditional lineal and angular measures.

\section{GEOMETRICS MORPHOMETRICS TRADITIONAL MORPHOMETRICS}

\begin{tabular}{|c|c|c|c|c|c|c|}
\hline PC & Eigenvalues & $\%$ & Cumulative & Eigenvalues & $\%$ & Cumulative \\
\hline & & Variance & $\%$ & & Variance & $\%$ \\
\hline 1 & 0.00268749 & 46.984 & 46.984 & 284.793 & 55.474 & 55.474 \\
\hline 2 & 0.00082253 & 14.380 & 61.363 & 99.4725 & 19.376 & 74.85 \\
\hline 3 & 0.00063975 & 11.184 & 72.548 & 72.2128 & 14.066 & 88.916 \\
\hline 4 & 0.00049552 & 8.663 & 81.211 & 25.9129 & 5.0475 & 93.963 \\
\hline 5 & 0.00034635 & 6.055 & 87.266 & 13.6864 & 2.6659 & 96.629 \\
\hline 6 & 0.00022149 & 3.872 & 91.138 & 6.14034 & 1.1961 & 97.825 \\
\hline 7 & 0.00016735 & 2.926 & 94.064 & 4.40517 & 0.85807 & 98.683 \\
\hline 8 & 0.00012719 & 2.224 & 96.287 & 2.98234 & 0.58092 & 99.264 \\
\hline 9 & 0.00010193 & 1.782 & 98.069 & 2.38246 & 0.46407 & 99.728 \\
\hline 10 & 0.00008003 & 1.399 & 99.468 & 1.00698 & 0.19615 & 99.924 \\
\hline
\end{tabular}




\section{FIGURE CAPTIONS}

Fig. 1 Measurement protocol on the mandible for linear and angular measurements with traditional morphometrics (a.), and landmarks definition for geometrics morphometrics (b.)

Fig. 2 Bar graphic for means of lineal and angle measurements for the three groups of mandibles, the variables definition are shown in the Fig 1a.

Fig. 3 Principal Components (PC) analyzed for mandibular shape with the three groups combined plots for the three first PCs scores: a) Plots for PC1 Vs PC2 and PC1 Vs PC3 obtained by GM and shape changes associated to three first PCs on the positive and negative score direction (scale factor 0.1 and -0.1 respectively). b) Plots for PC1 Vs PC2 and PC1 Vs PC3 obtained by traditional morphometrics.

Fig. 4 Shape difference between the group's average configurations. a) 3D surface models of each group average. b) Superimposition of the meshes between G1 and G3. 
a.

1 Condylion - Gonion Distance

2 Gonion-Menton Distance

3 Condylion-Menton Distance

4 Symphysis high

5 Body height at mental hole

6 Body height at retro-molar level

7 Ramus Width

8 Gonial Angle

9 Width Body posterior area

10 Symphysis Width

*g(left), d(right) b.

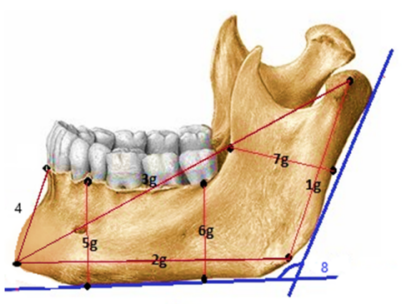

1 Col: Lateral Condyle

Rpos: Posterior Ramus

2 Go: Gonion

* AntGo: Antegonial

3 InfM: Infra-Mental

4 MF: Mental Foramina

5 SupM: Supra-Mental

6 Sy: Symphysis

7 Me: Menton

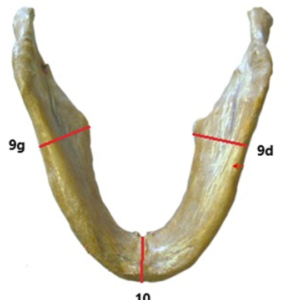

8 InfDe: Infradentale

9 MeSp: Mental Spine

10 RetMolExt: Retro-molar Externa

* RetMollnt: Retro-molar Internal

* Rant: Anterior Ramus

11 Cor: Coronoid

12 Colnt: Condyle Interne

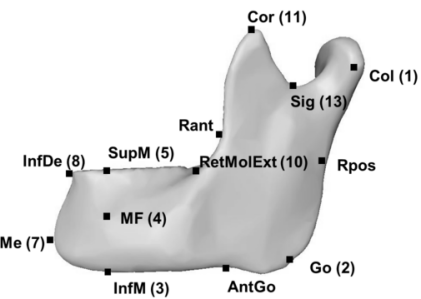

* CoSup: Condyle superior

13 Sig: Sigmoid notch.

*Landmarks excluded after error measurement test (repeatability)

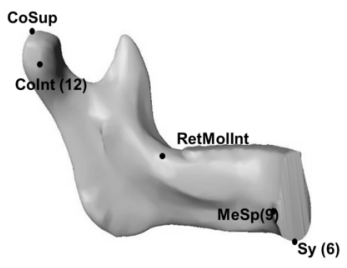




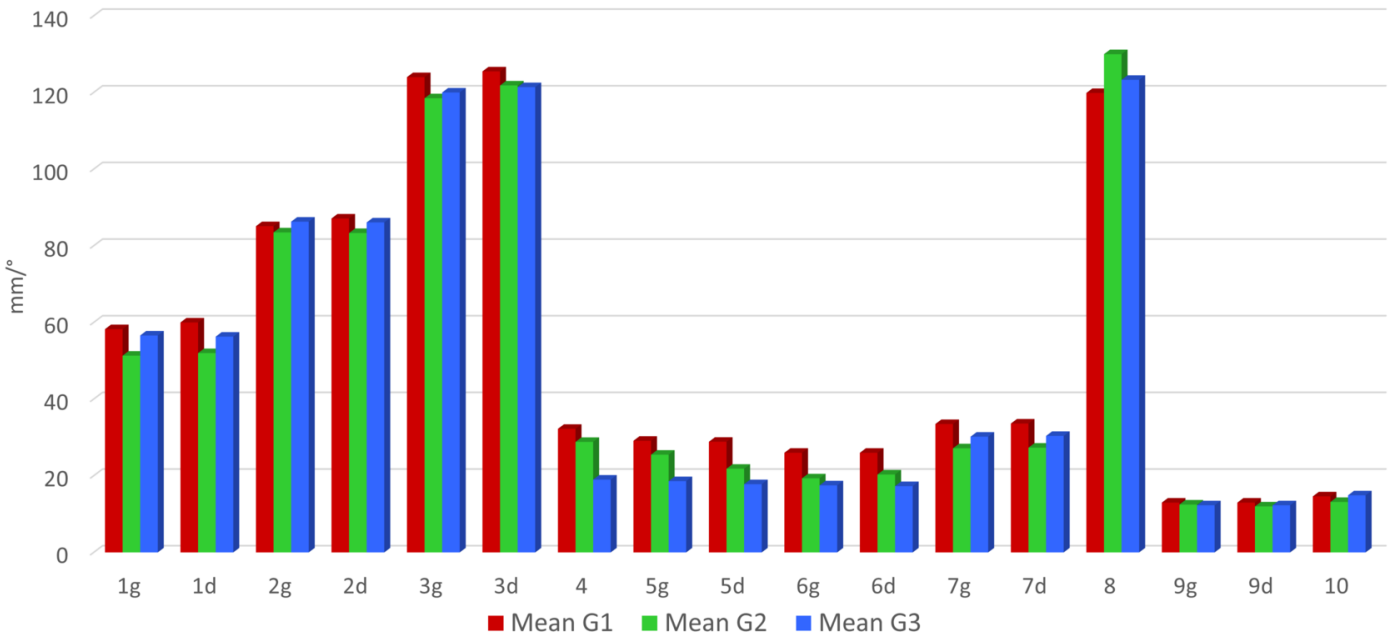




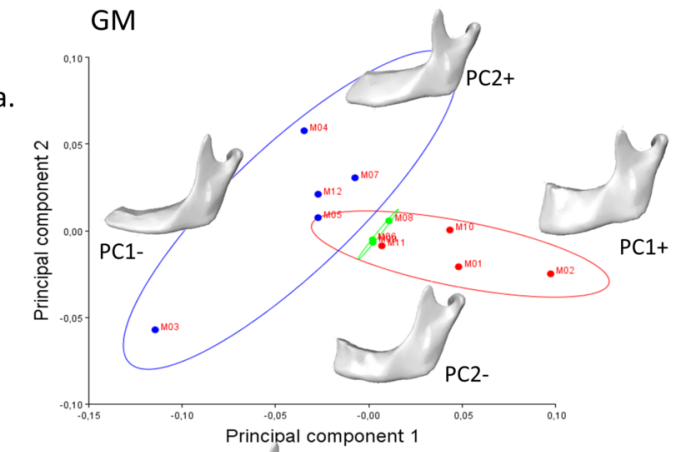

TRADITIONAL MORPHOMETRICS

G1

G2

G3

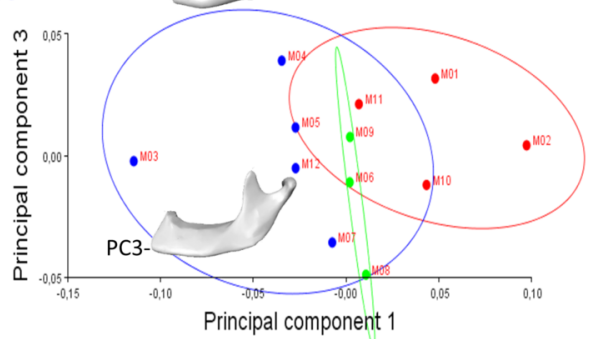

b.
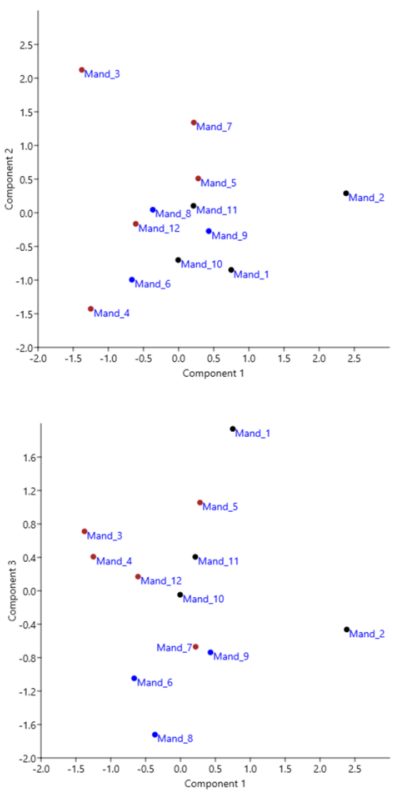
a.
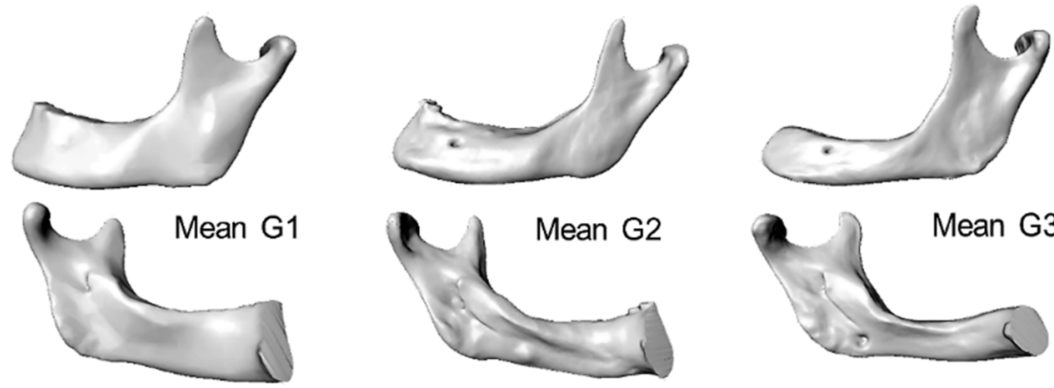

Mean G2

(2) Mean G3

b.

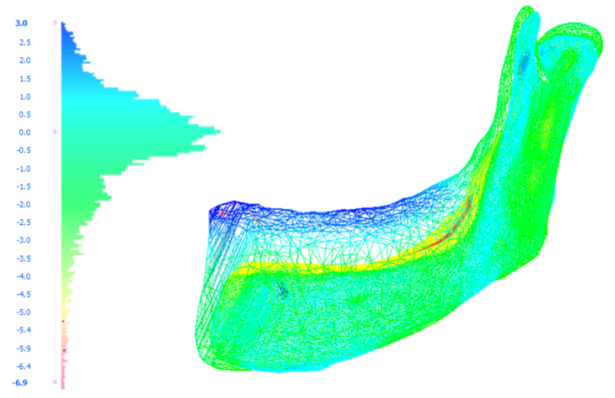

